\title{
DIELECTRIC USB-MOISTURE METER FOR SEEDS OF AGRICULTURAL CROPS
}

Aleksandr VOSTRUKHIN, Faculty of Mechanics and Technology, Department of Information Technologies and Electronics, Technological Institute of Service in Stavropol, Kulakova Prospect, 41/1, 355000, Stavropol, Russian Federation; avostrukhin@yandex.ru (corresponding author)

Elena VAKHTINA, Faculty of Electric Energy, Department of Electrical Engineering, Automation and Metrology, Stavropol State Agrarian University, Zootechnicheskiy Ln., 12, 355017, Stavropol, Russian Federation; eavakhtina@ yandex.ru

Maksim MASTEPANENKO, Faculty of Electric Energy, Department of Electrical Engineering, Automation and Metrology, Stavropol State Agrarian University, Zootechnicheskiy Ln., 12, 355017, Stavropol, Russian Federation; mma 26@inbox.ru Shaliko Gabrielyan, Faculty of Electric Energy, Department of Electrical Engineering, Automation and Metrology, Stavropol State Agrarian University, Zootechnicheskiy Ln., 12, 355017, Stavropol, Russian Federation; shaliko69@mail.ru

The modern technical development condition is closed due to tough business competitiveness, so the innovative information for teaching students on the best examples of engineering and designing is not available. This is one of the basic reasons that diminish engineering education effectiveness in the field of technical knowledge in modern agricultural production. The scientists of engineering departments work above the solution of this problem and adapt the results into practice-oriented teaching technologies. The example is the development of moisture meter for agricultural crops seeds on the world-famous microcontroller Arduino-based platform, oriented to master the foundations of real-time information technologies shown in this article. The principle of the moisture meter operation is based on the most common method for measuring humidity of seeds - dielectric technique. The classical algorithm of conversion, such as permittivity, capacitance, frequency, table-based transformations and temperature correction is given. In the research process the methods of software structural designing, including functionally-oriented techniques for realizing the functions of real-time information systems were used. The hardware and software for solving such tasks as measuring the humidity of crop seeds, as well as studying microcontroller devices operating on the base of classical measurement methods have been developed. It can be used to solve other engineering and scientific problems in the field of agriculture where capacitive sensors are used.

Keywords: Arduino, capacitance, frequency, measuring converter, microcontroller, temperature sensor.

\section{INTRODUCTION}

The task of systematizing scientific knowledge with the aim to give them to new generations will be always relevant. The modern technical development condition is closed due to tough business competitiveness, so the innovative information for teaching students on the best examples of engineering and designing is not available. For example, the information about realization of the converting temperature process into binary code by the well-known DS18B20 temperature sensor is not found. It is known that the accuracy of this sensor is $0.5^{\circ} \mathrm{C}$ for temperature range from -10 to $+80{ }^{\circ} \mathrm{C}(\mathrm{DS} 18 \mathrm{~B} 20$ Datasheet, 2017). In some cases it is deficiency accuracy. To improve accuracy of this sensor deeper knowledge of this device is required in comparison with the information presented in Datasheet. The authors also did not find information about hardware and software of the most popular farm electronic grain moisture meters, such as Wile, Multi-Graine, HE Lite.

The main purpose of this research is to develop hardware and software on which basis it is possible to solve engineering and educational tasks in the field of physical quantities measurement and control using capacitive sensors. The aim of the paper is to show the essence of constructing an electronic portable device for measuring the humidity of crops seed on an example of the dielectric USB-moisture meter.

USB-moisture meter is the system which consists of two subsystems: measuring subsystem and computer. This will make it possible to:

- improve USB-moisture meter providing new versions of software;

- use different opportunities of microprocessor technique, for example, to archive and convey the information of measurement results online.

\section{MATERIALS AND METHODS}

USB-moisture meter measuring subsystem consists of capacitance-to-frequency (output signal - frequency) measuring converter (MC) and microcontroller-based subsystem. The USB-moisture meter measuring subsystem is 
denoted as microcontroller measuring converter (MMC). MMC output information signal is carried through USB interface to the computer which displays measurement information.

We used NE555 chip of company Philips (NE555 Datasheet, 2017) for the MC formation. The capacitive sensor $C x$ as a time-setting element is shown in the Figures 1,2. The MC output signal goes to the Arduino Nano microcontroller system, where it is processed and in the final result form is sent to the PC. Arduino is well-known platform, implemented at popular microcontrollers of the AVR family (Blum, 2013). Arduino applications are developed in C / C ++ and Assembler languages - the most relevant and useful for real-time information systems (Vostrukhin et al., 2017), as well as in its own Wiring language. Arduino contains an extensive assortment of modular hardware and software with an open source license, continues to develop and is supported by such sistems as Matlab, AVR Studio and Windows 10. It is actively used both by professionals for the development of electronic systems, and educators for the training process at engineering faculties (Vostrukhin and Vakhtina, 2016).

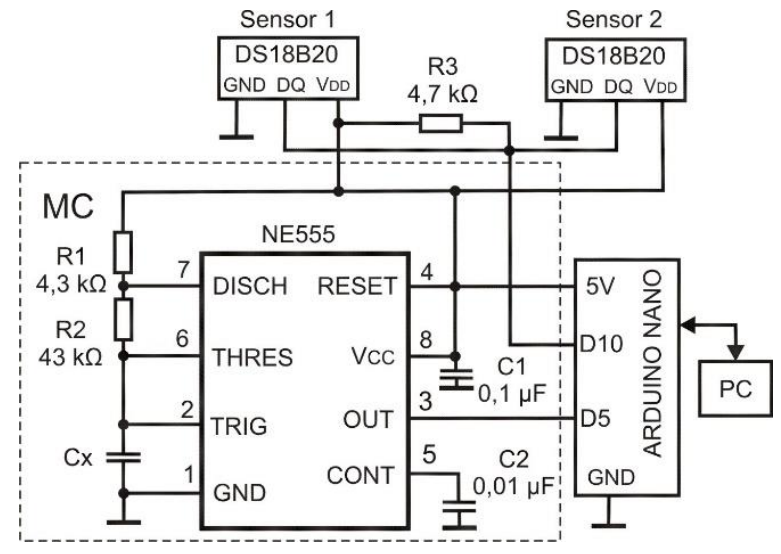

Figure 1. Schematic circuit diagram of USB-moisture meter

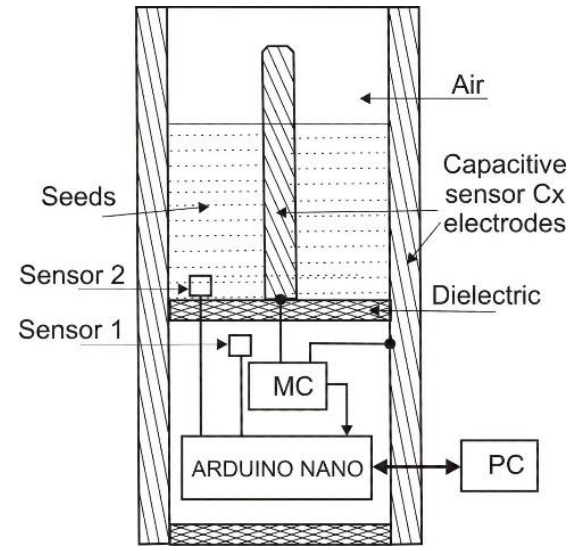

Figure 2. Construction of USB-moisture meter

The choice of NE555 chip for MC construction is explained by the following factors: a) technical

- the chip can be used in conjunction with the microcontroller as an alternative to analog-to-digital converters for implementing voltage-frequency-binary code conversion processes (Vostrukhin et al., 2015);

- all microcontrollers contain, as a rule, at least two hardware binary counters of rectangular pulses. This allows to organize a fixed time interval (a gate time) on one counter, and on the other - to count the pulses received at its input during this time interval;

b) didactic

- capacitance-to-frequency conversion is realized using transients flowing in RC-circuits and is organized with such classical devices as voltage comparator, RS-trigger, transistor switch and resistive voltage divider;

- the NE555 mathematical model is included in Multisim (NI Multisim, 2017), which is an industrystandard, best-in-class SPICE simulation environment and useful in the university programs of Design and Technology of Electronic Instrumentation.

Dielectric moisture meters operate in the frequency range from tens of $\mathrm{kHz}$ to tens of $\mathrm{MHz}$ (excluding super high frequency (SHF) moisture meters). The most common is the range from hundreds of $\mathrm{kHz}$ to $10-15 \mathrm{MHz}$. The conducted studies showed that the NE555 operates at a frequency up to $600 \mathrm{kHz}$ rather stably. The most common range of capacitance change of majority moisture meters, including the considered in this article, lies in the range from 5 to $25 \mathrm{pF}$.

The dependence of MC frequency from temperature during the investigation was found. MC output frequency decreased with increasing temperature. This dependence can be explained by increasing of NE555 transistor key resistance under the temperature influence. NE555 transistor key is designed for realization the periodic discharge processes of $C x$ capacitor shown in Figure 1. It was decided to use the microcontroller capabilities for correction the temperature influence by programming way. This solution makes possible does't complicate the device hardware by introducing a reference oscillator, for example, NE556 chip.

Two DS18B20 temperature sensors (Sensor 1 and Sensor 2 on Figures 1, 2) were introduced into moisture meter experimental sample for organization the temperature correction. Sensor 1 was introduced to correct the temperature influence on MC. It measures temperature of NE555 case. Sensor 2 was introduced to correct the temperature influence on permittivity of a seed sample. It measures temperature of a seed sample. There was necessary to solve the problem in such way that the MMC output signal did not change when the temperature of the USB-moisture meter was changed in the range from 10 to $30^{\circ} \mathrm{C}$.

Let us agree that $t_{m c}$ is the current MC temperature.

Then, $f_{m m c}$ frequency of the corrected MMC output signal in depending of $t_{m c}$ can be calculated according to equation (1): 


$$
f_{m m c}=f_{m c} \cdot\left[1+k_{f} \cdot\left(t_{m c}-t_{c m c}\right)\right],
$$

where: $f_{m c}-\mathrm{MC}$ output frequency at $t_{m c}$ temperature;

$t_{c m c}-\mathrm{MC}$ calibration temperature (most preferred $t_{c m c}=20^{\circ} \mathrm{C}$ );

$k_{f}$ - temperature coefficient of frequency (TCF), which characterizes the relative change in the MC output frequency with $t_{m c}$ temperature change by $1^{\circ} \mathrm{C}$.

For the temperature range from $t_{l m c}$ to $t_{2 m c}$, the TCF is defined according to equation (2):

$$
k_{f}=\frac{f_{2}-f_{1}}{f_{c m c} \cdot\left(t_{2 m c}-t_{1 m c}\right)},
$$

where: $f_{c m c}-\mathrm{MC}$ output frequency when $t_{c m c}$ calibration temperature.

For the case $C x=10 \mathrm{pF}$ and $f_{c m c}=420.0 \mathrm{kHz}$ there was experimentally established that at a temperature $t_{1 m c}=10$ ${ }^{\circ} \mathrm{C}$, the MC frequency was equal to $f_{1}=427.3 \mathrm{kHz}$, and at $t_{2 m c}=30^{\circ} \mathrm{C}$, respectively, $f_{2}=413.1 \mathrm{kHz}$. Then, in accordance with the expression (2), we determine:

$$
k_{f}=\frac{413.1-427.3}{420.0 \cdot(30-10)}=-0.0017 \mathrm{kHz} /{ }^{\circ} \mathrm{C}
$$

The TCF minus sign (-) indicates that the frequency of the MC output signal is inversely proportional to its temperature.

If the device is calibrated at a temperature different from $20^{\circ} \mathrm{C}$, you should find the average frequency of the entire range of change, as a sum of the extreme frequencies of the range divided by 2 . The obtained value of the average frequency must be substituted instead of $f_{c m c}$ value in equation (2).

\section{RESULTS}

Table 1 shows the results of experimental study the dependence of the frequencies $f_{m c}$ and $f_{c m c}$ on the temperature of NE555 chip and the capacitance $C x$. Output signal correction was performed accordance with the expression (1) for three values of the sensor capacitance $C x=5,10$ and $15 \mathrm{pF}$ at the TCF value $k_{f}=-0.0018\left[\mathrm{kHz} /{ }^{\circ} \mathrm{C}\right]$. This TCF value is obtained accordance with expression (2) for the case when $C x=5 \mathrm{pF}$. The nominal values of MC elements R1 and R2

\begin{tabular}{|c|c|c|c|c|c|c|c|c|c|c|c|c|}
\hline$C x, p F$ & $f,{ }^{t}{ }^{\circ} \mathrm{C}$ & 10 & 12 & 14 & 16 & 18 & 20 & 22 & 24 & 26 & 28 & 30 \\
\hline \multirow{2}{*}{5} & $f_{m c}$ & 512,6 & 511,5 & 510,5 & 508,4 & 506,4 & 504,7 & 502,7 & 501,1 & 499,5 & 497,8 & 496,0 \\
\hline & $f_{c m c}$ & 504,1 & 504,2 & 504,8 & 504,7 & 504,6 & 504,7 & 504,5 & 504,7 & 504,9 & 504,9 & 504,9 \\
\hline \multirow{2}{*}{10} & $f_{m c}$ & 427,3 & 425,8 & 424,2 & 422,6 & 421,4 & 420,0 & 418,4 & 417,2 & 415,7 & 414,2 & 413,1 \\
\hline & $f_{c m c}$ & 419,8 & 419,8 & 419,7 & 419,6 & 419,8 & 420,0 & 419,9 & 420,2 & 420,2 & 420,2 & 420,5 \\
\hline \multirow{2}{*}{15} & $f_{m c}$ & 368.4 & 367,0 & 365,6 & 364,3 & 363,3 & 362,3 & 361,3 & 360,0 & 359,2 & 358,1 & 356,9 \\
\hline & $f_{c m c}$ & 361,5 & 361,6 & 361,7 & 361,8 & 362,0 & 362,3 & 362,4 & 362,5 & 363,6 & 363,7 & 363,8 \\
\hline
\end{tabular}
are indicated in Figure 1.

Table 1. Dependence of the MC and MMC output frequencies $\left(f_{m c}\right.$ and $\left.f_{c m c}\right)$ from the NE555 temperature and $C x$ capacitance,

As a capacitive sensor $C x$, a variable capacitor with a calibrated scale (Figure 3 ) was used during the experiments. Such capacitor is a part of some measuring RLC-bridges. The general view of the developed USB-moisture meter is shown in Figure 4.

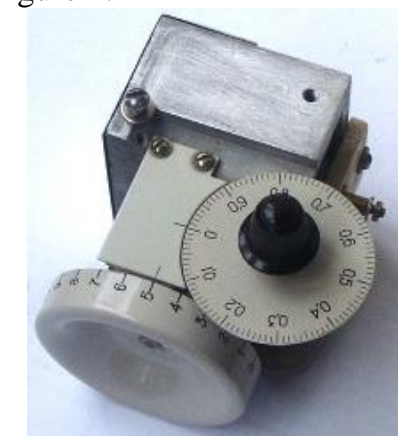

Figure 3. Variable capacitor with resolving power 0.01 $\mathrm{pF}$ and a capacitance change range rom 5 to $15 \mathrm{pF}$

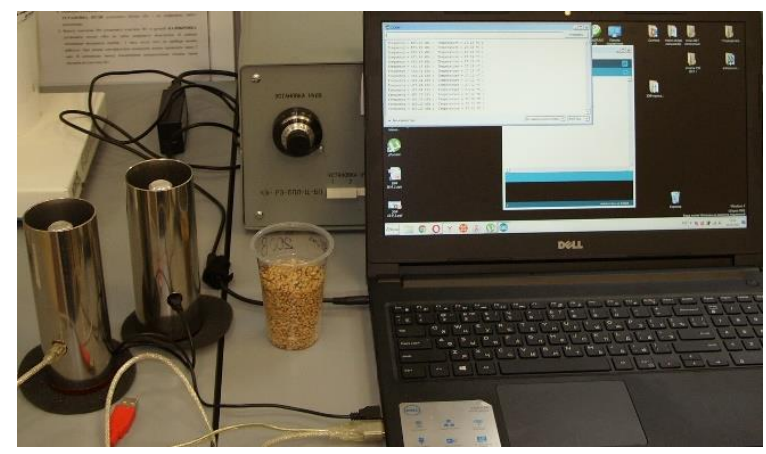

Figure 4. General view of the USB-moisture meter 
Based on the frequencies values $\left(f_{m c}\right)$ in Table 1, new refined TCFs were calculate accordance expression (2) for three capacitance values: $C x=5 p F, k_{f}=-0.0018 ; C x=10 p F, k_{f}=-0.0017 ; C x=15 p F, k_{f}=-0.0016$. Thus, the TCF is a function of the capacitance, i. e. $k_{f}=f(C x)$. This dependence can also be accounted by a programming way. But in our work this correction method is not considered, since the range of $C x$ capacitance change is relatively small and does not significantly affect to the moisture measurement.

Figure 5 shows the output frequencies changes of the MC and MMC vs. temperature of the NE555 chip for $C x=$ $15 \mathrm{pF}$, constructed using the Table 1 data.

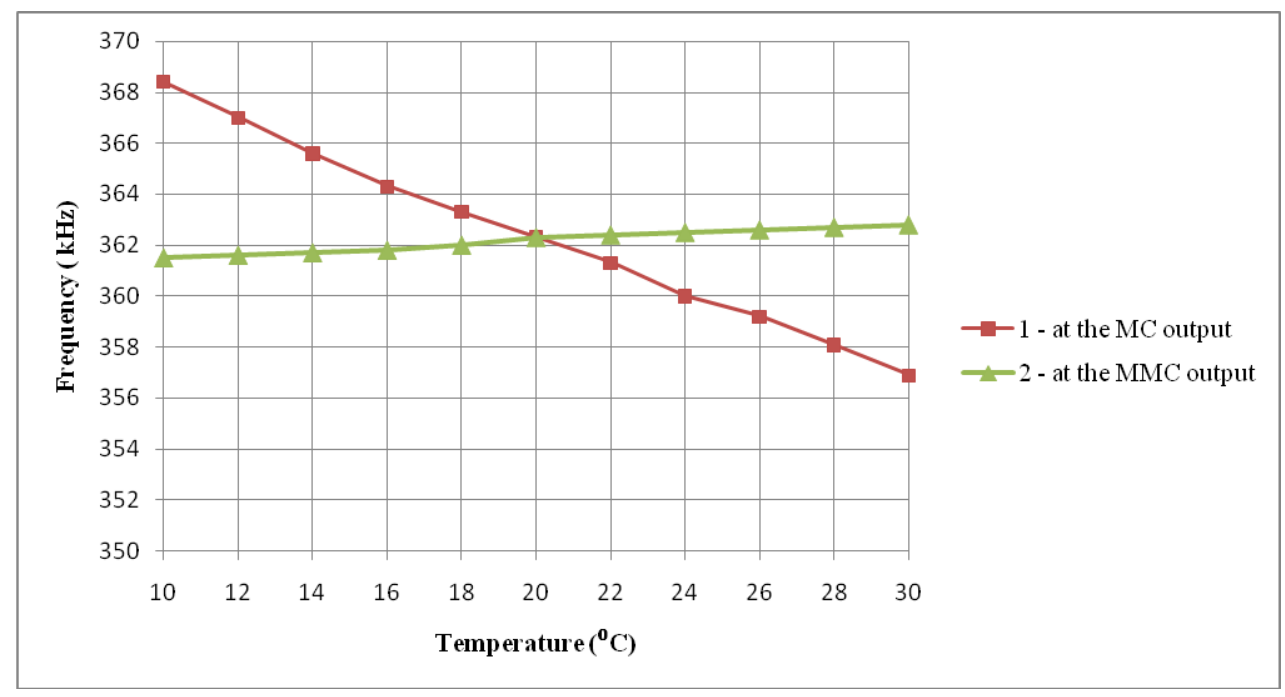

Figure 5. Output frequencies changes of the MC and MMC vs. temperature of the NE555

After correction the output frequency, MMC proceeds to its convertion into a humidity value. Frequency dependence from the seed sample moisture is given by the calibration table obtained as a result of the moisture meter calibration. This table is stored in the microcontroller flash memory. Cell addresses correspond to integer values rounded $f_{m m c}$ frequency. The microcontroller extracts from the memory, depending on the frequency value, the corresponding humidity values. Then, Sensor 2 measures $t_{h}$ temperature of the seed sample located in the $C x$ sensor case (Figure 2). The seed sample moisture value is corrected depending of this temperature according to equation (3).

$$
h_{0}=h_{c} \cdot\left[1+k_{h} \cdot\left(t_{h}-t_{h c}\right)\right] \text {, }
$$

where: $h_{c}$ - humidity value obtained from the calibration table;

$k_{h}$ - temperature coefficient of humidity $(\mathrm{TCH})$ that characterizes the relative change of the seed sample moisture measured by the dielectric method, when temperature change by $1^{\circ} \mathrm{C}$. In this case, the seed sample moisture remains unchanged, but its permittivity changes, which causes to change the $C x$ capacitance. As the temperature rises, the permittivity increases, and consequently the $C x$ capacitance also increases.

$t_{h c}$ - temperature at which the moisture meter calibration was performed $\left(t_{h c}=20{ }^{\circ} \mathrm{C}\right.$ is most preferred).

The coefficient $k_{h}$ is determined according to equation (4):

$$
k_{h}=\frac{h_{2}-h_{1}}{\frac{\left(h_{2}+h_{1}\right)}{2} \cdot\left(t_{2}-t_{1}\right)},
$$

where: $h_{1}$ and $h_{2}$-seed moisture values, which shown by the device at $t_{l}$ and $t_{2}$ temperatures respectively.

As the experiment result (Mastepanenko et al., 2017), it was found that at $t_{h c}=20{ }^{\circ} \mathrm{C}$ temperature of a wheat seed sample, the USB-moisture meter showed a moisture content of $14 \%$. The moisture content of the same seed sample measured by the standard air-heat drying method (Interstate Council for ..., 2015), was also 14\%. The USB-moisture meter showed humidity $h_{l}=13 \%$ at a seed sample temperature $t_{l}=10{ }^{\circ} \mathrm{C}$, and $h_{2}=15 \%$ at $t_{2}=30{ }^{\circ} \mathrm{C}$. Consequently, a sample temperature increase leads to overstating of the moisture meter indications. Then, according to equation (4), we find:

$$
k_{h}=\frac{15-13}{14 \cdot(30-10)}=0.0071\left[\frac{\%}{{ }^{\circ} C}\right]
$$

Figure 6 are the graphs illustrating dependence of MC output frequency from the wheat sample humidity for two dosing methods (volume- and weight-based) at calibration temperature $20^{\circ} \mathrm{C}$. In a case of the weight-based dosing, a seed 
sample weighing 70 grams was placed into the USB-moisture meter, so that the $C x$ central electrode was not completely covered with seeds. In a case of the volume-based dosing, the capacitive sensor was filled with seeds completely.

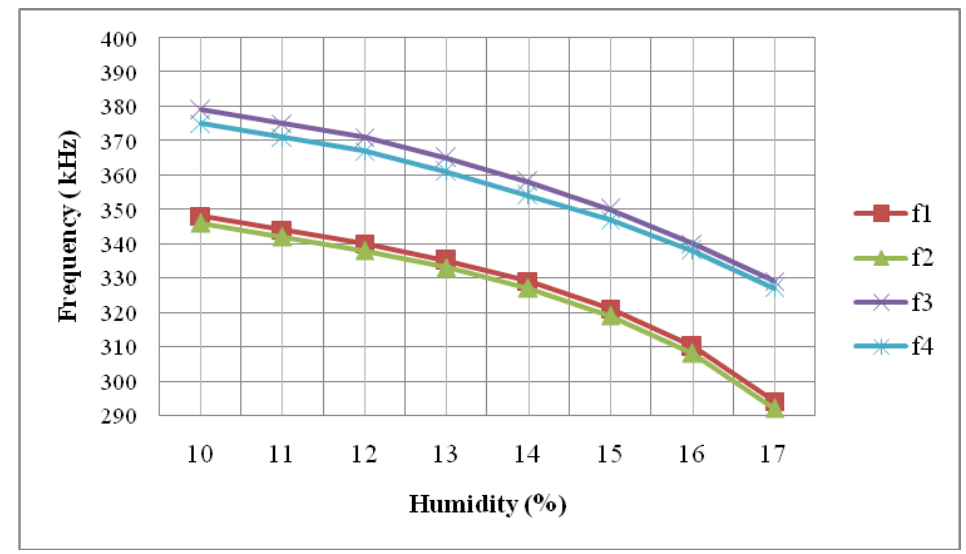

Figure 6. Output frequency change vs. humidity for two experimental USB-moisture meters, here $f_{1}$ and $f_{2}$ - the output frequency of the first and second moisture meters (weight-based dosing); $f_{3}$ and $f_{4}-$ the output frequency of the first and second moisture meters (volume-based doising)

The USB-moisture meter software development was carried out by a functionally-oriented method, which is consisting in the serial decomposition of the decided problem into separate components that have functional certainty (Cviklovic et al., 2011; Grinchenko, 2016). The software consists of 7 main functional modules:

1 - MC frequency measurements by MMC;

2 - MC temperature measurements by Sensor 1;

3 - Frequency correction depending on the MC temperature is carried out in MMC;

4 - Table conversion of the MMC frequency into humidity is carried out in MMC;

5 - The seed samples temperature measurements by Sensor 2;

6 - Correction of the seed sample humidity depending on its temperature is carried out in MMC;

7 - The output of results obtained in the preceding 6 modules to the computer monitor.

Thus, a computer monitor displays information allows you to control operation of all 6 program modules, three of which (1, 2 and 5) work with the device hardware. The USB-moisture meter algorithm and program will be in detail considered in a separate article.

\section{CONCLUSIONS}

The results of USB-moisture meter research show that the programming way of correction the temperature influence on measuring converter (MC) and permittivity of a seed sample are enough effective and allow to simplify the device hardware. The software implementation of most functions of the USB-moisture meter is realized with the Arduino Nano microcontroller device. This is due with the fact that the most effective solutions in creation of modern electronic systems are implemented on the microcontrollers' basics. In addition, the Arduino software contains a lot of libraries and project hubs. The Arduino software is free, it does not require a license and is always available on the producer's website (https://www.arduino.cc/). These Arduino advantages allow realizing other measuring USB-devices and use the example of the presented USB-moisture meter.

The USB-moisture meter program for measring the humidity of seed crops is based on a functionally-oriented method that allows users to see the results of intermediate transformations during the entire measurement process. It creates the opportunity to perfect the separate code modules and device operation throughout life cycle.

\section{ACKNOWLEDGEMENT}

This article is written as a result of the execution of the State Contract with the Ministry of Agriculture of Stavropol Territory No.143/17 from 22.08.2017.

\section{REFERENCES}

1. NE555 Datasheet. Available at http://www.ti.com/lit/ds/symlink/ne555.pdf (accessed on 27.12.2017).

2. Blum, J. 2013. Exploring Arduino: Tools and Techniques for Engineering Wizardry. Wiley. 384 p.

3. Cviklovič, V., Hrubý, D., Olejár, M., Lukáč, O. 2011. "Comparison of numerical integration methods in strapdown inertial navigation algorithm". Research in Agricultural Engineering. Vol. 57, Iss., pp. 30-34.

4. DS18B20 Datasheet. Available at https://cdn.sparkfun.com/datasheets/Sensors/Temp/DS18B20.pdf (accessed on 24.10.2017).

5. Grinchenko, V.A., Nikitenko G.V., Lysakov, A.A. and E.V. Konoplev (2016). Milking machine with electropulsator. Proceedings of the 15th International Scientific Conference "Engineering for Rural Development". Vol. 15, pp. 230-235. 
6. Interstate Council for Standartization. Metrology and Certification. 2015. State Standard 13586.5-2015. Zerno. Metod opredeleniya vlazhnosti. Gosudarstvennyy Standart (GOST) [State Standard 13586.5-2015 Grain. Method of moisture content determination], Standartinform, Moscow, Russia.

7. Mastepanenko, M.A., Vakhtina, E.A., Vostrukhin, A.V. et al. 2017. Razrabotka portativnogo cifrovogo ustrojstva dlya izmereniya vlazhnosti semyan sel'skohozyajstvennyh kul'tur: metodicheskie rekomendacii [Development of a portable digital device for measuring crop seeds humidity: guidelines], Stavropol State Agrarian University, Stavropol, Russia [In Russian]

8. NI Multisim. Available at http://www.ni.com/multisim (accessed on 29.10.2017).

9. Vostrukhin, A., Vakhtina, E. and Bondar, S. 2017. Using Assembler for microcontrollers' study on Arduino-based platform. Proceedings of the 16th International Scientific Conference "Engineering for Rural Development". Vol. 16, pp. 581-587. http://www.tf.llu.lv/conference/proceedings2017/Papers/N115.pdf.

10. Vostrukhin, A. and Vakhtina, E. 2016. Studying Digital Signal Processing on Arduino Based platform. Proceedings of the 15th International Scientific Conference "Engineering for Rural Development". Vol. 15, pp. $236-241$. http://www.tf.llu.lv/conference/proceedings2016/Papers/N043.pdf.

11. Vostrukhin, A. V., Habarov, A. N. and Zarochentsev, I.A. 2015. Mikrokontrollernyj izmeritel'nyj preobrazovatel' soprotivleniya, emkosti i napryazheniya $v$ dvoichnyj kod [Microcontroller-based converter of resistance, capacitance and voltage into binary code], Stavropol, Russia, Pat. 2565813. http://www1.fips.ru/Archive/PAT/2015FULL/2015.10.20/Index_ru.htm. [In Russian] 